\title{
Selegiline increases heme oxygenase-1 expression and the cytotoxicity produced by dopamine treatment of neuroblastoma SK-N-SH cells
}

C.R.M. Rieder ${ }^{1}$,

A.C. Williams ${ }^{2}$ and D.B. Ramsden ${ }^{3}$

\author{
1Departamento de Neurologia, Hospital de Clínicas de Porto Alegre, \\ Porto Alegre, RS, Brasil \\ Departments of ${ }^{2}$ Clinical Neuroscience and ${ }^{3}$ Medicine, \\ The University of Birmingham, Queen Elizabeth Hospital, Birmingham, UK
}

\section{Correspondence \\ C.R.M. Rieder \\ R. Ten. Cel. Fabrício Pilar, 945/402 \\ 90450-040 Porto Alegre, RS \\ Brasil \\ E-mail: carlosrieder@terra.com.br}

Received September 1, 2003 Accepted April 19, 2004

\begin{abstract}
Increased dopamine catabolism may be associated with oxidative stress and neuronal cell death in Parkinson's disease. The present study was carried out to examine the effect of dopamine on the expression of heme oxygenase-1 and -2 (HO-1 and HO-2) in human neuroblastomas (SK-N-SH cell line) and the effects of selegiline and antioxidants on this expression. Cells were kept with close control of $\mathrm{pH}$ and were incubated with varying concentrations of dopamine (0.1-100 $\mu \mathrm{M})$ for $24 \mathrm{~h}$. HO- 1 and HO-2 cDNA probes were prepared by reverse transcription-polymerase chain reaction amplification. The mRNA expression of HO-1 and HO-2 was measured by Northern blot analysis. The levels of HO-1 mRNA increased after dopamine treatment, in a dose-dependent manner, in all cell lines studied, whereas levels of the two HO-2 transcripts did not. The HO-1 and HO-2 protein expression was analyzed by Western blotting. HO-1 protein was undetectable in untreated SK-N-SH cells and increased after treatment with dopamine. In contrast, the HO-2 protein $(36 \mathrm{kDa})$ was detected in untreated cells and the levels did not change as a result of treatment. $\alpha$-Tocopherol (10$100 \mu \mathrm{M})$ and ascorbic acid $(100 \mu \mathrm{M})$ did not attenuate the effects of dopamine. Selegiline $(10 \mu \mathrm{M})$ produced significant increase $(\mathrm{P}<$ 0.01 ) in the induction of HO-1 by dopamine (more than six times the control values). The increased expression of HO-1 following dopamine treatment indicates that dopamine produces oxidative stress in this cell line.
\end{abstract}

\section{Introduction}

Idiopathic Parkinson's disease (IPD) is characterized by a loss of dopamine in the striatum caused by degeneration of dopaminergic neurons in the zona compacta of the
Key words

- Oxidative stress

- Parkinson's disease

- Dopamine

- Selegiline 
matic (monoamine oxidase B; MAO-B) and nonenzymatic pathways (2). Thus, dopamine itself may be the primary agent at the heart of the degenerative process. Furthermore, selegiline, a specific inhibitor of MAO$\mathrm{B}$, is commonly used in conjunction with L3,4-dihydroxyphenylalanine (levodopa) in the treatment of IPD.

Heme oxygenase $(\mathrm{HO})$ is the rate-limiting enzyme in heme catabolism. It catalyzes the degradation of heme to biliverdin, with the concurrent release of iron and carbon monoxide $(5,6)$. In humans two HO isoenzymes, the products of distinct genes, have been characterized to date $(7,8)$. HO-1, an inducible enzyme, is a stress response protein (6). $\mathrm{HO}-1$, but not HO-2, is strongly induced by heme, metals, sulfhydryl compounds, hormones, and certain adverse conditions such as oxidative stress (9-11). The chemical diversity of HO-1 inducers has led to the speculation that $\mathrm{HO}-1$, in addition to its role in heme degradation, may also have a vital function in maintaining cellular homeostasis (12). Thus, regulation of HO-1 may have a role in conferring cytoprotection to vulnerable neurons in the presence of sustained oxidative stress. Increased HO-1 expression has been reported in neurodegenerative diseases, such as Alzheimer disease and IPD (13-16). HO-1 immunoreactivity has been recently demonstrated in the substantia nigra Lewy bodies of IPD $(16,17)$. However, the cause and significance of the altered expression are unclear. It has been reported that dopamine induces the expression of $\mathrm{HO}-1$ in glial-derived cell lines and human endothelial cells $(18,19)$.

In this study we investigated the effects of dopamine on the levels of mRNAs encoding HO- 1 and HO- 2 and protein levels in SK$\mathrm{N}-\mathrm{SH}$ neuroblastoma, a catecholaminergic human cell line, to determine whether these cells express HO-1 and whether expression is related to cell survival. The effect of selegiline and antioxidants on $\mathrm{HO}$ regulation was also investigated.

\section{Material and Methods}

\section{Treatment with dopamine}

The human neuroblastoma (SK-N-SH) cell line was obtained from the European Collection of Animal Cell Cultures, Porton Down, Salisbury, UK. The cells were cultivated in Dulbecco's modified Eagle's medium supplemented with $10 \%$ fetal calf serum, L-glutamine $(2 \mathrm{mM})$, penicillin $(100 \mathrm{U} / \mathrm{ml})$, and streptomycin $(100 \mu \mathrm{g} / \mathrm{ml})$ (Sigma, Poole, UK). Cells were kept in a humidified cell culture incubator at $37^{\circ} \mathrm{C}$ under $5 \% \mathrm{CO}_{2}$ with close control of $\mathrm{pH}$.

On day 2 after plating (about $70 \%$ of cell confluence) the cells were treated with 0.1$100 \mu \mathrm{M}$ dopamine (Sigma, St. Louis, MO, USA) for $24 \mathrm{~h}$. Flasks maintained under the same conditions but without exposure to the drugs served as control.

\section{Treatment with dopamine and antioxidants}

On day 2 after plating, SK-N-SH cells were treated with either 10 or $100 \mu \mathrm{M}$ dopamine plus either selegiline $(10 \mu \mathrm{M})$ or $\alpha$ tocopherol $(10,50,100 \mu \mathrm{M})$ or ascorbic acid $(100 \mu \mathrm{M})$, or the appropriate control solution. Dopamine, ascorbic acid and $\alpha$-tocopherol were purchased from Sigma, and selegiline was obtained from Aldrich Chemical Company Inc. (Milwaukee, WI, USA).

\section{mRNA estimation by Northern blotting}

HO- 1 and HO- 2 cDNA probes were prepared by reverse transcription-polymerase chain reaction (RT-PCR) amplification of total SK-N-SH RNA. Oligonucleotide primers were obtained from Alta Bioscience (Birmingham, UK). The HO-1 forward primer, 5' CCA AGT TCA AGC AGC TCT ACC GC 3 ' (position 607) and reverse primer 5' CCA CGG TAA GGA AGC CAG CC 3' (position 1023) were predicted to produce a 436-bp product (Genbank accession code file: 
X06985); HO-2 forward primer, 5' ATG TCA GCG GAA GTG GAA ACC 3' (position 85) and reverse primer 5' GCC AAG AGT CCA GCA GCT AGG 3' (position 990) were predicted to produce a 926-bp product (Genbank accession code file: S34389). Between the upper and lower primers there is at least one intron to differentiate the RT-PCR product from that produced by genomic DNA amplification. PCR, using a hot start technique, was performed in a final volume of $50 \mu \mathrm{l}$ consisting of $1 \mu \mathrm{l}$ of the reverse transcribed product, $5 \mu \mathrm{l}$ of Taq $10 \times \mathrm{NH} 4$ buffer, $5 \mu \mathrm{l}$ of $2.5 \mathrm{mM}$ dNTP's, $5 \mu \mathrm{l}$ of 10 $\mu \mathrm{M}$ forward primer, $5 \mu \mathrm{l}$ of $10 \mu \mathrm{M}$ reverse primer, $1.5 \mu \mathrm{l}$ of $50 \mathrm{mM} \mathrm{MgCl} 2,27 \mu \mathrm{l}$ of Milli-Q water, and $0.5 \mu \mathrm{l}$ of Taq polymerase enzyme (Promega, Southampton, UK). The thermocycler conditions used were the following: $93^{\circ} \mathrm{C}$ for $30 \mathrm{~s}$ (denaturation), $60^{\circ} \mathrm{C}$ for $30 \mathrm{~s}$ (annealing) and $72^{\circ} \mathrm{C}$ for $30 \mathrm{~s}$ (extension) performed for 30 cycles. To exclude the chances of cross-hybridization with other sequences, the sequence was compared with Genebank entries using the Genetics Computer Group FASTA program. The PCR-amplified cDNA of human HO-1 and HO-2 yielded amplification products of the expected size, as confirmed by DNA sequencing.

Total RNA ( $2 \mu \mathrm{g} / \mathrm{lane})$, isolated from the cell lines using RNAzol ${ }^{\mathrm{TM}} \mathrm{B}$ reagent (AMS Biotechnology, Benelux, UK) was electrophoresed on $1.0 \%$ agarose gel containing 2.2 $\mathrm{M}$ formaldehyde, transferred to a Hybond- $\mathrm{N}$ nylon membrane (Amersham, Little Chalfont, UK) and fixed by UV irradiation. The blots were probed with ${ }^{32} \mathrm{P}$-labeled cDNAs (HO$1, \mathrm{HO}-2$ and B-actin) by the method of Sambrook et al. (20). The relative amounts of radiolabeled cDNA that hybridized to the blots were quantified by densitometric analysis of autoradiograms (LKB 2202 laser densitometer, Pharmacia Biotech, St. Albans, UK) and normalized to $\beta$-actin levels to control for loading errors. $\mathrm{HO} / \mathrm{\beta}$-actin signal ratio was set at an arbitrary value of 1 in control experiments (untreated control). Experiments were repeated at least three times.

\section{HO-1 protein estimation by Western blotting}

For the Western blot analysis, cells were lysed with $10 \%$ Triton X-100 and vortexing. Soluble lysate samples $(20 \mu \mathrm{g}$ protein/lane determined by BioRad DC protein assay; BioRad Laboratories, Watford, UK) were fractionated by SDS/polyacrylamide gel electrophoresis, and transferred to a nitrocellulose membrane using a Trans-Blot transfer cell (Pharmacia Biotech). Membranes were exposed to rabbit anti-HO-1 or anti-HO-2 (Affinity Research Products Limited, Exeter, UK) diluted 1:1000 and then to alkaline phosphatase conjugated sheep anti-rabbit IgG (1:2000) (Binding Site Limited, Birmingham, UK) and the color was developed using Sigma Fast ${ }^{\mathrm{TM}}$ BCIP/NBT tablets prepared according to manufacturer instructions.

\section{Cell viability}

Cell viability was assessed by Trypan blue exclusion and by lactate dehydrogenase (LDH) release assays (21). The viability of treated cells was expressed as percentage in relation to the untreated cells. Cytotoxicity was measured using the CytoTox $96{ }^{\circledR}$ Assay from Promega. This method indirectly measures the release of LDH. For this assay the cells were plated and treated in 96-well cell culture plates and the assay was performed according to manufacturer instructions.

\section{Lipid peroxidation assay}

Lipid peroxidation was assessed in SK$\mathrm{N}-\mathrm{SH}$ cells treated with either 0 or $100 \mu \mathrm{M}$ dopamine by the assay of malonaldehyde using the Oxis International Inc. kit (R\&D Systems Ltd., Abingdon, UK) according to manufacturer instructions for cultured cells (approximately $5 \times 10^{6}$ cells per extraction). 
The amount of malonaldehyde determined was corrected for protein extracted, assayed by the method of Bradford (22).

\section{Results}

Effects of dopamine on steady-state levels of HO-1 and HO-2 mRNA and intracellular protein and on cell viability

Dopamine induced HO-1 mRNA expression in the SK-N-SH cell line in a dosedependent manner, as shown in Figure 1. HO-2 mRNA was detected as two bands of $\sim 1.4$ and $\sim 2.4 \mathrm{~kb}$. Expression of HO-2 mRNA did not change significantly in either the $\sim 1.4$ - or $\sim 2.4-\mathrm{kb}$ transcript in dopamine-
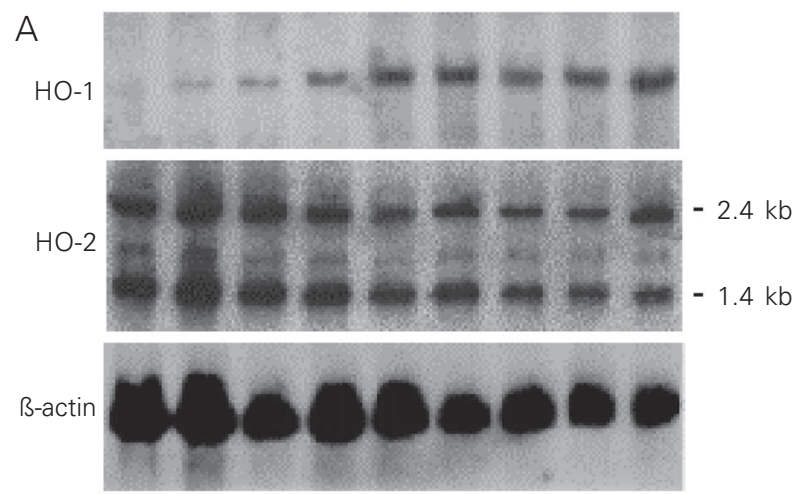

$\begin{array}{lllllllll}0 & 0.1 & 1.0 & 2.5 & 5.0 & 10 & 25 & 50 & 100\end{array}$

[Dopamine] $(\mu \mathrm{M})$

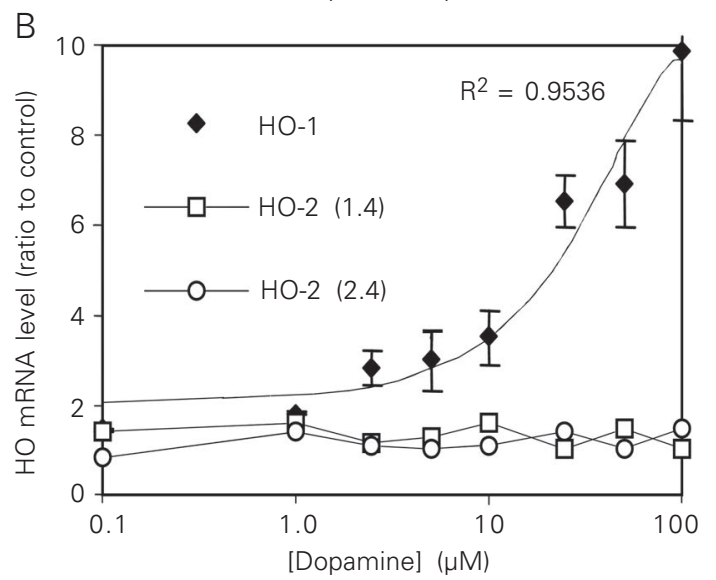

Figure 1. Effects of exposure to dopamine on the levels of heme oxygenase 1 and 2 (HO-1 and HO-2) mRNA in SK-N-SH cells. A, Northern blot analysis. Cells were treated for $24 \mathrm{~h}$ with increasing concentrations of dopamine (0.1-100 $\mu \mathrm{M})$. B, Relative expression levels of HO-1 mRNA. Data are reported as means \pm SEM $(N=3)$. treated cells.

HO-1 (32 kDa) protein was not detected in the control (not treated with dopamine) homogenates from SK-N-SH but was present at detectable levels after treatment with dopamine $(1-100 \mu \mathrm{M})$. HO-2 protein was observed in untreated cells and the levels did not change as a result of dopamine treatment (Figure 2).

Up-regulation of HO-1 was inversely correlated with survival. Exposure to increasing dopamine concentrations was cytotoxic to the SK-N-SH cell line analyzed. Increasing exposure to dopamine caused a progressive decrease in cell viability assessed by LDH release and Trypan blue exclusion. The survival of treated cells expressed as percentage of the viable untreated cells was as follows: $100 \%$ with $0.1 \mu \mathrm{M}$ dopamine, $100 \%$ with $1 \mu \mathrm{M}$ dopamine, $62 \%$ with $10 \mu \mathrm{M}$ dopamine, $54 \%$ with $50 \mu \mathrm{M}$ dopamine, and $42 \%$ with $100 \mu \mathrm{M}$ dopamine. The experiments were repeated six times. The percentages of cytotoxicity, estimated by LDH release for SK-N-SH (repeated five times) were as follows: $0 \%$ with 0.1 dopamine, $0 \%$ with $1 \mu \mathrm{M}$ dopamine, $14 \%$ with $10 \mu \mathrm{M}$ dopamine, $21 \%$ with $50 \mu \mathrm{M}$ dopamine, and $29 \%$ with $100 \mu \mathrm{M}$ dopamine. HO-1 mRNA levels were inversely correlated with cell survival in each case. Dopamine toxicity positively correlated with HO-1 induction.

The decrease in cell survival as a result of dopamine exposure was accompanied by an increase in lipid peroxidation. Malonaldehyde levels in untreated cells and in cells treated with $100 \mu \mathrm{M}$ dopamine ranged respectively from undetectable to $0.071 \mu \mathrm{M}$ and from 0.056 to $0.37 \mu \mathrm{M}$ malonaldehyde/mg extracted protein $(\mathrm{N}=6$ extractions per group; $\mathrm{P}<$ 0.01, Mann-Whitney U-test).

Effect of antioxidants on dopamine-induced HO-1 expression in SK-N-SH cells

Dopamine-induced reduction in cell viability was not attenuated by antioxidants $(\alpha-$ 
tocopherol and ascorbic acid). The dopamine induction of HO-1 mRNA in the SK-NSH cell line $(10$ and $100 \mu \mathrm{M})$ was not affected by L-ascorbic acid or by $\alpha$-tocopherol treatment at concentrations of 100 $\mu \mathrm{M}$ and $50 \mu \mathrm{M}$, respectively. In contrast, combined selegiline at $10 \mu \mathrm{M}$ and dopamine treatment at 10 and $100 \mu \mathrm{M}$ increased the expression of HO-1 mRNA and reduced significantly the level of cell viability compared with the results obtained with dopamine alone (Figures 3 and 4).

\section{Discussion}

Exposure to dopamine induced steadystate HO-1 mRNA levels in the human neuroblastoma SK-N-SH cell line. Neuroblastoma derives from embryonic sympathetic tissue and these cells have been widely used as an in vitro model system to investigate catecholamine metabolism in Parkinson's disease. In contrast, the two HO-2 transcripts were evident in all cell lines tested and were not induced by dopamine treatment. Levels of intracellular HO-1 protein mirrored the changes seen with the mRNA. The pattern of regulation observed here was similar to that seen in other situations where oxidative stress was induced, i.e., HO-1 is highly sensitive, whereas HO-2 is refractory (23). Given that dopamine metabolism generates oxidative free radicals, as evidenced again here by the increase in lipid peroxidation products, the induction of HO-1 seen here would seem to be a consequence of the formation of these free radicals. In another study, pre-treatment of cultured C6 glioma cells with a dopamine antagonist failed to attenuate HO-1 induction by dopamine. This suggested that dopamine induction of $\mathrm{HO}-1$ is not mediated by conventional dopamine receptors. This conclusion was supported by the finding that neither D1 nor D2 agonists activated HO-1 expression in C6 cells (18).

Co-exposure to classical and therapeutic antioxidants failed to attenuate the dopamine-
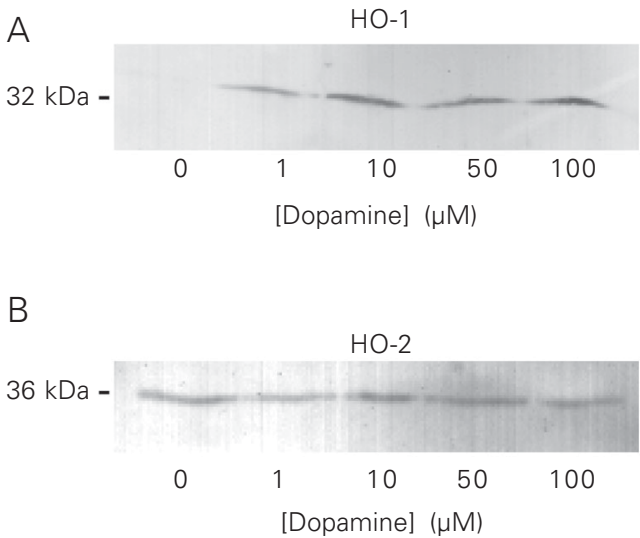

Figure 2. Effect of dopamine treatment on $\mathrm{HO}$ protein expression in SK-N-SH cell line. A, Immunoblot of the homogenate incubated with anti-HO-1 (1:2000). B, Immunoblot of the homogenate incubated with anti-HO-2 (1:2000). The molecular weight is shown on the left. Twenty micrograms of protein was loaded per lane.
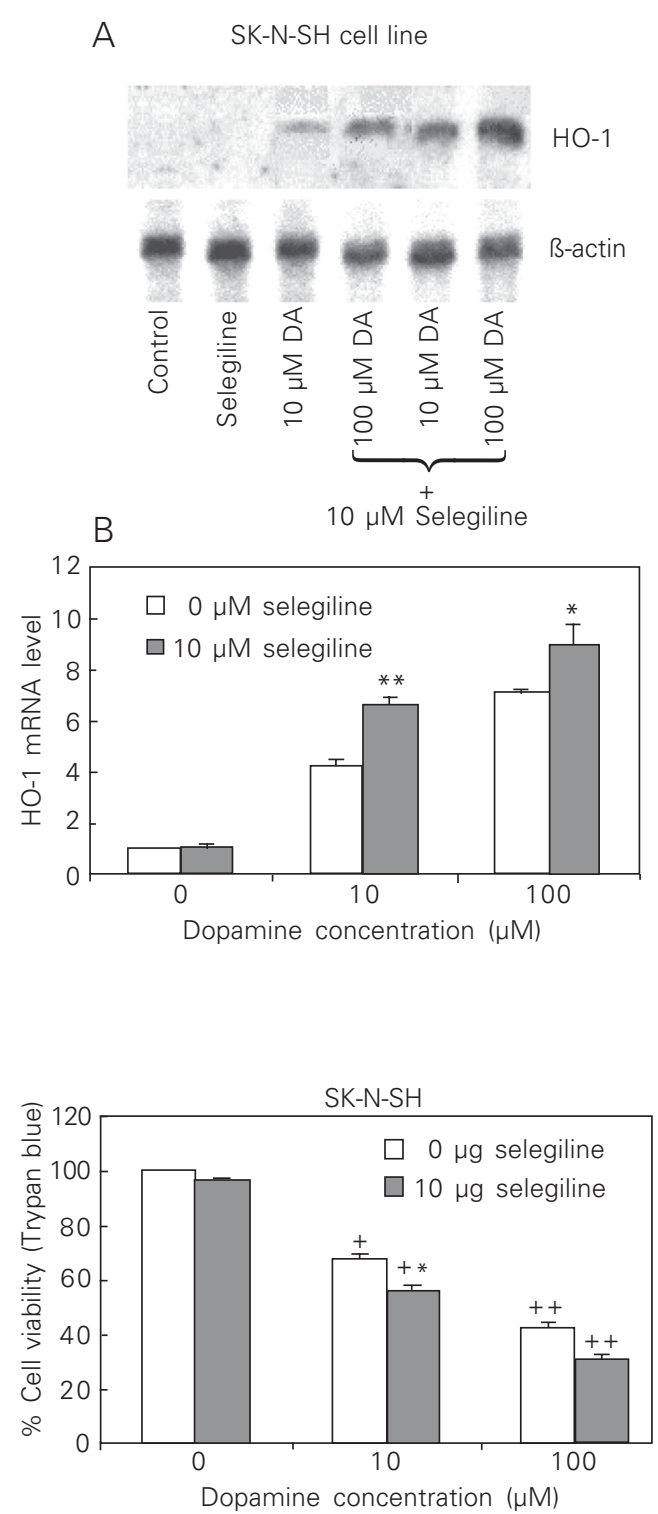

Figure 3. Effect of selegiline on the levels of HO-1 mRNA in the SK-N-SH cell line exposed to dopamine for 24 h. A: Northern blot analysis. $B$ : Relative expression levels of HO-1 mRNA. Data are reported as means \pm SEM $(\mathrm{N}=5) . \mathrm{DA}=$ dopamine ${ }^{*} \mathrm{P}<$ 0.05 and ${ }^{*} P<0.01$ compared with $0 \mu \mathrm{M}$ selegiline at $10 \mu \mathrm{M}$ or $100 \mu \mathrm{M}$ dopamine (two-way ANOVA pairwise comparisons).
Figure 4. Effect of $10 \mu \mathrm{M}$ selegiline on the survival of SK-N-SH cells exposed to dopamine. Data are reported as means \pm SEM $(N=5)$. Statistical analyses were by two-way ANOVA with pairwise comparisons. $+P<$ 0.05 and $++P<0.001$ compared with $0 \mu \mathrm{M}$ selegiline at 0 $\mu \mathrm{M}$ dopamine; ${ }^{*} \mathrm{P}<0.05 \mathrm{com}$ pared with $0 \mu \mathrm{M}$ selegiline at $10 \mu \mathrm{M}$ or $100 \mu \mathrm{M}$ dopamine. 
induced increase in HO-1 expression and reduction in cell viability. Rather, selegiline, a specific MAO-B inhibitor, enhanced dopamine-induced HO-1 expression and reduced cell viability further compared with treatment with dopamine alone. This would suggest that the antioxidants were rapidly metabolized or were in a separate intracellular compartment compared with that where the free radicals were generated. Nevertheless, the antioxidant results agree with the assessment of their therapeutic effectiveness in vivo.

A similar observation of an in vitro cytotoxic effect of selegiline has been shown in SH-SY5Y cells treated with dopamine (24). The results suggest that the toxic effect of dopamine is enhanced by selegiline. Dopamine levels would of course be increased due to the blocking of oxidative deamination by selegiline. The mechanism of selegiline-enhanced toxicity, however, is still unclear. The lack of effect of MAO-B inhibitors suggests an involvement of enzymatic mechanisms in dopamine toxicity. Overall, it appears that the toxicity of dopamine involves more auto-oxidation than enzymatic metabolism to produce reactive oxygen species. If dopamine auto-oxidation results in toxicity, this may occur via reactive semiquinone or quinone formation, leading to generation of free radicals. Although selegiline by itself did not produce any change in HO1 expression, cells exposed to dopamine plus selegiline showed higher levels of HO-1 mRNA compared to cells exposed to dopamine only.

Selegiline rather than reducing the dopamine-induced toxicity in vitro actually enhances it. This finding seems to be related to a controversial issue, namely, that selegiline can cause an increase of the mortality of Parkinson's disease patients following chronic treatment with the drug (25).

Selegiline alters the gene expression of HO-1 in neuroblastoma cell lines treated with dopamine. This is perhaps an indication that the interaction between selegiline and dopamine exacerbates the cytotoxicity to SK-N$\mathrm{SH}$ cells. Interestingly, research has shown that selegiline can induce altered expression of a number of genes in neurons including the genes for superoxide dismutase 1 and 2 and catalase $(26,27)$. It has been suggested that the above changes in gene expression appear to reduce oxidative radical damage (28). Nevertheless, our findings suggest that selegiline in fact may be toxic to dopaminergic cells treated with dopamine, and that $\mathrm{HO}$ induction may possibly be induced by an increase in the oxidative stress condition. Because the enzymatic route is inhibited, more toxic radicals could be formed by a non-enzymatic pathway.

Our findings suggest that the apparent toxic effect by selegiline observed in some in vivo (25) and in vitro (24) studies may be due to potentiation of dopamine toxicity. The mechanism of selegiline-enhanced toxicity, however, is still unclear.

Many studies have suggested that HO-1 is a major cell defense protein, assisting other antioxidant systems in protecting cells from oxidative stress $(9,10)$, particularly when the levels of other cellular antioxidant systems are inadequate, as in IPD (29), because bilirubin is an effective scavenger of reactive oxygen species. However, increased levels of carbon monoxide and iron may not necessarily be beneficial (30). In the absence of the ability to synthesize ferritin, free iron may initiate oxidative radical formation. Even if ferritin synthesis is stimulated, it is possible that effective concentrations may not be achieved in the nuclear compartment, the site where ferritin is most needed to chelate iron (31). Interestingly, elevated iron levels with unchanged ferritin levels have been identified in the substantia nigra of IPD patients (32), and iron deregulation in the brain is thought to contribute to oxidative damage in both Alzheimer's disease and IPD $(33,34)$. Carbon monoxide, a possible neurotransmitter, is akin to nitric oxide in that it is capable of 
stimulating cyclic guanosine monophosphate production $(35,36)$. Generated in excess in disease states, however, carbon monoxide possesses cellular effects that may impair cell vitality (31).

The present study showed that dopamine induces HO-1 in the neuroblastoma cell line and induction is inversely correlated with cell viability. The increased HO-1 expression is strongly indicative that dopamine produces oxidative stress in these cell lines, but coexposure to dopamine and antioxidants did not attenuate the induction or the effects of dopamine on cell viability.

\section{References}

1. Hirsch EC (1994). Biochemistry of Parkinson's disease with special reference to the dopaminergic systems. Molecular Neurobiology, 9: $135-142$

2. Olanow CW (1992). An introduction to the free-radical hypothesis in Parkinson's disease. Annals of Neurology, 32: S2-S9.

3. Jenner P (1994). Oxidative damage in neurodegenerative disease. Lancet, 344: 796-798.

4. Simonian NA \& Coyle JT (1996). Oxidative stress in neurodegenerative diseases. Annual Review of Pharmacology and Toxicology, 36: 83-106.

5. Maines M (1988). Heme oxygenase: function, multiplicity, regulatory mechanisms, and clinical applications. FASEB Journal, 2: 2557-2568

6. Abraham NG, Drummond GS, Lutton JD \& Kappas A (1996). The biological significance and physiological-role of heme oxygenase. Cellular Physiology and Biochemistry, 6: 129-168.

7. Shibahara S, Sato M, Muller R \& Yoshida T (1989). Structural organization of the human heme oxygenase gene and the function of its promoter. European Journal of Biochemistry, 179: 557-563.

8. McCoubrey WK, Ewing JF \& Maines MD (1992). Human heme oxygenase-2 - characterization and expression of a full-length cDNA and evidence suggesting that the $2 \mathrm{HO}-2$ transcripts may differ by choice of polyadenylation signal. Archives of Biochemistry and Biophysics, 295: 13-20.

9. Keyse SM \& Tyrrell RM (1989). Heme oxygenase is the major 32$\mathrm{kDa}$ stress protein induced in human-skin fibroblasts by UVA radiation, hydrogen-peroxide, and sodium arsenite. Proceedings of the National Academy of Sciences, USA, 86: 99-103.

10. Applegate LA, Luscher P \& Tyrrell RM (1991). Induction of heme oxygenase: a general response to oxidant stress in culturedmammalian-cells. Cancer Research, 51: 974-978.

11. Ewing J \& Maines M (1991). Rapid induction of heme oxygenase 1 mRNA and protein by hyperthermia in rat brain: heme oxygenase 2 is not a heat shock protein. Proceedings of the National Academy of Sciences, USA, 88: 5364-5368.

12. Choi AMK \& Alam J (1996). Heme oxygenase-1: function, regulation, and implication of a novel stress-inducible protein in oxidantinduced lung injury. American Journal of Respiratory Cell and Molecular Biology, 15: 9-19.

13. Castellani R, Smith MA, Richey PL, Kalaria R, Gambetti P \& Perry G (1995). Evidence for oxidative stress in Pick disease and corticobasal degeneration. Brain Research, 696: 268-271.

14. Premkumar DRD, Smith MA, Richey PL, Petersen RB, Castellani R, Kutty RK, Wiggert B, Perry G \& Kalaria RN (1995). Induction of heme oxygenase-1 messenger-RNA and protein in neocortex and cerebral vessels in Alzheimer's disease. Journal of Neurochemis- try, 65: 1399-1402.

15. Schipper HM \& Stopa EG (1995). Expression of heme oxygenase1 in the senescent and Alzheimer-diseased brain. Annals of Neurology, 37: 758-768.

16. Castellani R, Smith MA, Richey PL \& Perry G (1996). Glycoxidation and oxidative stress in Parkinson disease and diffuse Lewy body disease. Brain Research, 737: 195-200.

17. Schipper HM, Liberman A \& Stopa EG (1998). Neural heme oxygenase-1 expression in idiopathic Parkinson's disease. Experimental Neurology, 150: 60-68.

18. Schmidt J, Mertz K \& Morgan JI (1999). Regulation of heme oxygenase-1 expression by dopamine in cultured C6 glioma and primary astrocytes. Brain Research: Molecular Brain Research, 73: 50-59.

19. Berger SP, Hunger M, Yard BA, Schnuelle P \& Van Der Woude FJ (2000). Dopamine induces the expression of heme oxygenase-1 by human endothelial cells in vitro. Kidney International, 58: 23142319.

20. Sambrook J, Fritsch EF \& Maniatis T (1989). Molecular Cloning: $A$ Laboratory Manual. 2nd edn. Cold Spring Harbor Laboratory Press, New York.

21. Moldeus P, Hogbord J \& Orrenius S (1978). Isolation and use of liver cells. Methods in Enzymology, 52: 60-71.

22. Bradford MM (1976). A rapid and sensitive method for the quantitation of microgram quantities of protein utilizing the principle of protein-dye binding. Analytical Biochemistry, 72: 248-254.

23. Kutty RK, Kutty G, Nagineni CN, Hooks JJ, Chader GJ \& Wiggert B (1994). RT-PCR assay for heme oxygenase-1 and heme oxygenase-2: a sensitive method to estimate cellular oxidative damage. Annals of the New York Academy of Sciences, 738: 427-430.

24. Lai CT \& Yu PH (1997). Dopamine- and L-beta-3,4-dihydroxyphenylalanine hydrochloride (L-DOPA)-induced cytotoxicity towards catecholaminergic neuroblastoma SH-SY5Y cells - Effects of oxidative stress and antioxidative factors. Biochemical Pharmacology, 53: 363-372.

25. Parkinson's Disease Research Group of the United Kingdom (1995). Comparison of therapeutic effects and mortality data of levodopa and levodopa combined with selegiline in Parkinson's disease. British Medical Journal, 16: 1602-1607.

26. Carrillo MC, Kitani K, Kanai S, Sato Y, Miyasaka K \& Ivy GO (1994). Deprenyl increases activities of superoxide dismutase and catalase in certain brain regions in old male mice. Life Sciences, 54: 975981.

27. Kitani K, Kanai S, Carrillo MC \& Ivy GO (1994). (-)Deprenyl increases the life span as well as activities of superoxide dismutase and catalase but not of glutathione peroxidase in selective brain regions 
in Fischer rats. Annals of the New York Academy of Sciences, 717: 60-71.

28. Tatton WG \& Chalmersredman RME (1996). Modulation of geneexpression rather than monoamine-oxidase inhibition (-)deprenylrelated compounds in controlling neurodegeneration. Neurology, 47: S171-S183.

29. Sian J, Dexter DT, Lees AJ, Daniel S, Agid Y, Javoyagid F, Jenner $P$ \& Marsden CD (1994). Alterations in glutathione levels in Parkinson's disease and other neurodegenerative disorders affecting basal ganglia. Annals of Neurology, 36: 348-355.

30. Nutter LM, Sierra EE \& Ngo EO (1994). Heme oxygenase does not protect human cells against oxidant stress. Journal of Laboratory and Clinical Medicine, 123: 506-514.

31. Nath KA (1994). The functional-significance of induction of home oxygenase by oxidant stress. Journal of Laboratory and Clinical Medicine, 123: 461-463.
32. Mann VM, Cooper JM, Daniel SE, Srai K, Jenner P, Marsden CD \& Schapira AHV (1994). Complex-I, iron, and ferritin in Parkinson's disease substantia nigra. Annals of Neurology, 36: 876-881.

33. Dexter DT, Carayon A, Javoy-Agid F, Agid Y, Wells F, Daniel S, Lees A, Jenner P \& Marsden C (1991). Alterations in the levels of iron, ferritin and other trace metals in Parkinson's disease and other neurodegenerative diseases affecting the basal ganglia. Brain, 114: 1953-1975.

34. Connor JR \& Menzies SL (1995). Cellular management of iron in the brain. Journal of the Neurological Sciences, 134: 33-44

35. Marks GS, Brien JF, Nakatsu K \& McLaughlin BE (1991). Does carbon-monoxide have a physiological-function. Trends in Pharmacological Sciences, 12: 185-188.

36. Verma A, Hirsch DJ, Glatt CE, Ronnett GV \& Snyder SH (1993). Carbon-monoxide: a putative neural messenger. Science, 259: 381-384. 